of $1535,1540,1579$ and 1592 against forestalling and regrating, and the English Acts of $1266,1353,1533$ and particularly of 1549 and 1552 on the same subjects.

Prof. Hunter discusses the legislation setting up the Monopolies Commission and its work, particularly the general Report on Collective Discrimination of 1955 , which led to the Restrictive Trade Practines Act, 1956. This Act is in turn examined very thoroughly', particularly the fundamental Section 21, which established the rule that a restriction in pursuance of any agreement under review was to be deemed contrary to the public interest, unless the Court were satisfied of at least one of seven stated sets of circumstances, and also that the restriction was 'not unressonablo'. The author devotes two chapters to the operation of judicial review, as exemplified by the cases hitherto contested, considering the criteria established by the Act, and various defects in the processes.

Prof. Hunter then turns to resale prico maintenance, which is a newer subject of judicial control and on which we have as yet no judicial guidance and where the operation of the legal control has yet to become apparent, and concludes by discussing monopoly, oligopoly and merger. In general Prof. Hunter finds tho present system satis. factory; indeed, he considers the Monopolies Commission "an investigatory instrument of great flexibility and potential range", but he has a number of recommendations for change in the present legislative structure, most of which appear to have substantial merit.

The book is very readable, despite an unfortunate number of phrases masquerading as sentences, and not overburdened with technicality, and its carefully analysed exposition of the present situation presents a clear and fair picture.

DAVID M. WALKER

\section{MAGNETISM DIGEST}

\section{Magnetism and Magnetic Materials}

1965 Digest-a Survey of the Technical Literature of the Preceding Year. Edited by R. L. White and K. A. Wickersheim. Pp. xiii +260 . (New York: Academic Press, Inc.; London: Acadomic Press, Inc. (London), Ltd., 1965.) $88 s$.

$\mathrm{HE}$ problem of keeping abreast of the scientific literature in any field of research is immense. As a partial solution to this problem, for several years the American Institute of Physies and Institute of Electrical and Electronic Engineers, on the occasion of their annual conferences on magnetism and magnetic materials in the United States, have sponsored the production of a Magnetic Materials Digest. These volumes contain references, drawn from a large number of sources, to work in the field of magnetism and magnetic materials published in the preceding year. They therefore provide a very convenient way of surveying the work done in a particular field of magnetism over the previous years.

The 1965 Digest differs slightly from its predecessor. There has been a change in title to emphasize that it is not a manufacturer's source book and the volume has a new, improved format following a change in publisher. Those readers familiar with previous volumes in the series will find the usual changes in chapter and section headings reflecting the changes of interest and emphasis in magnetism research. The Bell Telephono Laboratories Index to the Literature of Magnetism has again been the principal source of references, more than sixteen hundred of which are listed, the great majority having been published in 1964 .

If the number of publications is taken as a measure of interest in a topic, then for 1964, non-metals, theory, soft magnetic materials and thin films head the list in that order. However, these numbers may be misleading because the contents of some papers are such that they are, or could have been, referred to in more than one chapter. An outstanding example is that of the chapter on superconductivity which in Magnetism and Magnetic Materials has nineteen references compared with 208 in the Digest for 1964. Many of the papers on superconducting phenomena now appear in their more natural places rather than in a special chaptor of their own.

J. H. Phillips

\section{SCIENTIFIC BIOGRAPHIES}

\section{Geschichte der Mikroskopie}

Leben und Werk Grosser Forscher. Herausgegeben von Hugo Freund und Alexander Berg. Unter Mitarbeit Namhafter Autoren. Band 1: Biologie. Pp. xv +375 . Band 2: Medizin. Pp. xv+506. (Frankfurt am Main: Umschau Verlag, 1963, 1964.) n.p.

VOLUMES 1 and 2 of Geschichte der Mikroskopie form the first in a collection of short biographios of scientists written mostly by German authors. A third volume dealing with the physical sciences and technology is in preparation. Despite the title, most of the subjects are people who have used the microscope as a tool and only a minority have made any contribution to microscopy as such. Judging from modorn experience, one might comment wryly that possibly many of them had little knowledge of either the instrument itself or of the proper way to use it. A sceptic might answer that this is unimportant because optics is such a poor way of forming images in any event; after all, even a perfect lens trying to form an image of a point source only manages to get about 84 per cent of the light anywhere near the right place! All the same, one might still wish to see fewer stopped down or lowered condensers, badly tilted mirrors and uncentred lamps at allegedly scientific demonstrations.

Volume 1 begins with a general review by the editors covering the history and the development and applications of microscopy. The treatment is inevitably sketchy and occasionally irritating, as when the name of C. R. Burch is omitted from the discussion of reflecting microscopes. The bibliography, however, is quite extensive and useful. In general the bibliographies are one of the most valuable features of the book; each chapter is followed by a selection of the papers of the subject himself as well as related references. Another pleasant feature is the inclusion of a good photograph or portrait of cach subject.

$I_{t}$ is only to be expected that major prominence is given to German scientists. In Volume l, for examplo, no British names appear and only four American (Chambers, MeClung, Minot and Wilson) out of a total of thirty articles. Ono might have thought that at least one out of Brown, Bowman, Hardy, Sharpey-Schäfer or Strangeways merited inclusion. Histochemistry is poorly represented and Raspail, one of the founders of the subject, is not mentioned. W. Flemming, the great German cytologist, and the Swede, Retzius, who produced such a fantastic volume of illustrated work with the microscope, are other surprising omissions.

Volume 2, dealing with medicine, contains forty-six articles, of which three are on American and threo on British workers. The latter include Alexander Fleming and Grafton Elliott-Smith; truly the word 'microscopy' is liberally interpreted!

When all this is said, however, these books do make pleasant reading and several of the great names in microscopy such as Abbé, Harting, Köhler, Naegeli, Schwendener, Strugger, Ambronn, Purkinje and Valentin are to be found, as well as a host of others distinguished in the use of the microscope as an essential tool in thoir biological or medical research. Collections of this sort can always be eriticized for their choice of material but on the whole this is a welcome addition to the literature of scientific biography.
R. BARER 